\title{
Optimization of supercritical fluid extraction of phytosterol from roselle seeds with a central composite design model.
}

\begin{abstract}
Recovery of phytosterol from roselle (Hibiscus sabdariffa L.) seeds via supercritical carbon dioxide extraction modified with ethanol was investigated at pressures of 200-400 bar, temperatures from 40 to $80{ }^{\circ} \mathrm{C}$ and at supercritical fluid flow rates from 10 to $20 \mathrm{ml} / \mathrm{min}$. It was found that an entrainer such as ethanol could enhance the solubility and extraction yield of roselle seed oil from the seed matrix, compared to values obtained using supercritical $\mathrm{CO} 2$. After a typical run (holding period of $30 \mathrm{~min}$, continuous flow extraction of $3 \mathrm{~h}$ ), the results indicate that the oil recovery was optimal with a recovery of $108.74 \%$ and a phytosterol composition of $7262.80 \mathrm{mgkg}-1$ at relatively low temperature of $40 \circ \mathrm{C}$, a high pressure of 400 bar and at a high supercritical fluid flow rate of $20 \mathrm{ml} / \mathrm{min}$ in the presence of $2 \mathrm{ml} / \mathrm{min}$ $\mathrm{EtOH}$ as entrainer. The solubility of roselle seed oil increased with temperature at the operating pressures of 200, 300 and 400 bar. Supercritical fluid extraction involved a short extraction time and the minimal usage of small amounts of entrainer in the $\mathrm{CO} 2$.
\end{abstract}

Keyword: Carbon dioxide; Optimization; Phytosterol; Response surface methodology; Roselle seed oil; Supercritical fluid extraction. 